\title{
Poverty Status, Health Behaviours and Health: Implications for Social Assistance and Health Care Policy
}

\author{
Deanna L. Williamson \\ Faculty of Nursing \\ University of Alberta \\ Edmonton, Alberta \\ JANET E. FAST \\ Department of Human Ecology \\ University of Alberta \\ Edmonton, Alberta
}

Cette étude a examiné les liens entre le statut de pauvreté, les comportements en matière de santé et la santé de 130 Albertains vivant au sein de familles pauvres. Pour les fins de cette étude, le statut de pauvreté indiquait si les familles pauvres recevaient de l'assistance sociale et profitaient de soins de santé complets gratuits ou plutôt si elles travaillaient sans avoir accès à des soins de santé gratuits. Les résultats de sept analyses différentes indiquent que le statut de pauvreté était relié de diverses façons à la santé des participants. Plus particulièrement, les répondants pauvres qui travaillaient étaient généralement en meilleure santé que ceux sur l'assistance sociale sauf lorsque ces premiers n'étaient pas en mesure de payer pour leurs prescriptions parce qu'ils n'en avaient pas les moyens. L'article se termine sur une discussion des implications de ces découvertes sur les politiques d'assistance sociale et de soins de santé.

This study investigated the relationships among poverty status, health behaviours, and the health of 130 Albertans living in poor families. For the purposes of this study, poverty status indicated whether poor families were receiving social assistance along with comprehensive health care benefits or whether they were working poor without comprehensive health care benefits. Findings from seven separate path analyses indicate that poverty status was differentially related to the health of participants. Specifically, working poor respondents were found to be generally healthier than their social assistance counterparts except in those instances in which the working poor were prevented from filling needed prescriptions because they lacked the economic resources to do so. The paper concludes with a discussion of the implications of these findings for social assistance and health care policies.

\section{INTRODUCTION}

$\mathrm{O}$ ne of the greatest challenges confronting policymakers across Canada is the increasing incidence of family poverty. From 1981 to 1993 the poverty ${ }^{1}$ rate among Canadian families ${ }^{2}$ increased from 11.3 percent to 14.5 percent. This translates into an increase of more than 300,000 poor families. As a result, there were more than one million Canadian families living in poverty in 1993. At a more local level, Alberta's family poverty rate increased from the lowest of any province in Canada 
in 1981 (7.2 percent) to the third highest provincial rate in 1993 (15.1 percent) (Centre for International Statistics, Canadian Council on Social Development 1996; Ross et al. 1994). ${ }^{3}$

Reflecting their heterogeneity, poor families can be categorized in a number of ways. Two such broad categorizations are working poor families and families that receive social assistance. These two groups of poor families differ with respect to their source of income and their eligibility for in-kind benefits. Working poor families receive at least one-half of their total income from family members who are employed (Hess 1987; Family Service Association of Edmonton and the Income Security Action Committee 1991). On the other hand, families that receive social assistance obtain the majority of their income from government sources. In Alberta, most of these families also are eligible for a variety of in-kind benefits, including comprehensive health care (Alberta Family and Social Services 1994). Comprehensive health care benefits allow for the provision of services beyond those provided by $\mathrm{Al}$ berta Health Care. ${ }^{4}$ Examples of these comprehensive benefits include dental benefits, and coverage for eye glasses and a wide range of medications. Many working poor families do not have access to these types of comprehensive health care benefits (Family Service Association of Edmonton and Income Security Action Committee 1991; Williamson and Fast 1993). In short, in Alberta comprehensive health care benefits are not equally available to all families living in poverty. It is this distinction that was the focus of this study.

A number of serious consequences of poverty have been identified in previous research. One such consequence is suggested by the demonstrated relationship between poverty and poor health (Adams 1993; Duffy 1989; Hay 1988; Hirdes et al. 1986; Manga 1993; Roberge et al.1995; Wilkins 1988; Wilkins et al. 1989; Wilkins et al. 1991). Moreover, research findings have suggested that individuals who live in families that receive social assistance have lower levels of health than those individuals who live in working poor families (Williamson and Fast 1993).

Despite an undeniable relationship between poverty and poor health, income is not the sole determinant of health. In fact, as the health promotion movement gained strength during the 1970s and 1980 s, it was increasingly acknowledged that health is determined, in part, by individual health behaviours such as involvement in physical/recreational activities, sleep, preventative health examinations, smoking, and consumption of alcohol (Ashton and Seymour 1993; Health Eduction Unit, WHO 1993; Ott 1990; Segovia et al. 1989; Tanner 1991). This emphasis on individual health behaviours suggests that the health of people living in poor families, which tends to be less than that of their non-poor counterparts, is related to the behaviours in which they choose to engage. Is this a fair conclusion to draw?

With the expansion of health promotion in the 1990 s, to a movement that assumes a socioenvironmental perspective of health, it increasingly is contended that it is not in fact fair to place sole responsibility for health on individuals. Concern has been expressed that the emphasis on individual responsibility masks the effects of social, economic, and political factors on health behaviour choices available to individuals living in poor families (Frank 1995; Labonte 1995; Milio 1988; Stevens and Hall 1992). It has been argued by a number of authors and researchers that health care and social policies, such as those that regulate social assistance programs and those that result in the differential availability of comprehensive health care benefits, often determine the cost and availability of health care services that are available to poor families. It has been further argued that, as a consequence, these policies influence the choices available to individuals living in poor families with respect to the health behaviours in which they are able to engage (Brand et al. 1977; Health Education Unit, WHO 1993; Mahler 1988; Meister 1993; Family Service Association of Edmonton and Income Security Action 
Committee 1991). However, there is little evidence to support this contention.

In summary, research findings have provided evidence that poverty is associated with poor health, and that health is in part determined by individual health behaviours. Nonetheless, little is known about the relationships among the constraints on healthrelated choices imposed by health care and social policies, the health behaviours engaged in by individuals living in poor families, and the subsequent health of these people. To gain a better understanding of some of these relationships, this study explored the relationships that poverty status has with both the health behaviours engaged in by people living in poor families and the health of these individuals. The term poverty status indicates whether poor families were receiving social assistance accompanied by comprehensive health care benefits or whether they were working poor that did not have comprehensive health care benefits. For the purposes of this study, health was conceptualized as a positive state of physical and psychological well-being that is integral to quality of life. In other words, health is not only an end, but it is also a resource which provides people with opportunities to make choices and to lead socially and economically productive lives (Epp 1986; Mahler 1981; Siler-Wells 1988; World Health Organization 1987).

\section{Methods}

\section{Sampling}

A purposive sample of 130 people living in either working poor families or in families receiving social assistance was recruited from an assortment of human service agencies in Edmonton. Some of the agencies included the Boyle Street Co-op, Edmonton's Food Bank, the CANDORA Society, Norwood Community Service Centre, and the Edmonton Board of Health. In an attempt to increase the degree to which the sample represented people living in families receiving social assistance and people living in working poor families, the agencies through which participants were recruited vary with respect to both the programs they offer the needs of the people they serve. For example, the Boyle Street Co-op and the Food Bank tend to serve people who are very "needy," in that they have difficulties meeting their basic needs. On the other hand, people who access agencies such as the CANDORA Society and Norwood Community Service Centre tend to use these agencies to participate in programs such as parenting classes or Collective Kitchens rather than because they are in crisis. In addition, because public health nurses at the Edmonton Board of Health have regular contact with families that are not necessarily experiencing crises, they recruited a number of participants who were not clients of the other agencies through which participants were recruited.

Selection of the sample was based on a variety of criteria. First, study participants were those whose gross family income was below the Statistics Canada low income cut-offs (LICOs) ${ }^{5}$ during the 12 months preceding their involvement in the study. Second, participants were divided into two groups according to their family's poverty status. Social assistance participants included people living in families that, for the 12 months prior to their participation in the study, received the majority of their income from social assistance. In addition, the families in which these participants lived had been receiving comprehensive health care benefits during the previous 12 months. Working poor participants included people living in families that, for the past 12 months, received more than one-half of their income from family members who were employed. The families in which these participants lived had not received comprehensive health care benefits during the 12 months preceding their involvement in the study.

\section{Operationalization of Variables}

The concepts of interest in the study included poverty status, health behaviours, and health. Poverty status, which was measured by a dichotomous variable, indicated whether participants lived in families receiving social assistance accompanied by comprehensive health care benefits (1) or whether 
they lived in working poor families that did not receive comprehensive health care benefits $(0)$.

Using a series of self-report measures, three categories of health behaviours were measured: health promoting, health damaging, and treatment focused. The health promoting behaviours that were measured included sleep, exercise, home dental care, preventative medical examinations, and preventative dental examinations. Operationalization of these health promoting behaviours is summarized in Table 1.

Smoking and alcohol consumption were the health damaging behaviours that were measured. Table 2 summarizes the operationalization of these behaviours. Table 3 outlines the operationalization of the treatment-focused health behaviours, which included prescription medication treatment, dental treatment, and medical treatment.

TABLE 1

Operationalization of Health Promoting Behaviours

Variable

Sleep:

Exercise:

Home dental care:

Preventative dental care:

Preventative medical care:
The typical number of hours of sleep/24 hours.

Number of times per typical week participants reported engaging in at least 20 minutes of exercise.

An ordinal variable that measured the frequency with which participants reported brushing their teeth:

1. Once a week or less

2. 2-6 times a week

3. Once a day

4. At least twice a day

A dummy variable that measured whether participants had a dental check-up or cleaning in the 12 months preceding the interviews ( $1=$ Yes and $0=\mathrm{N}_{0}$ ).

A dummy variable that measured whether, in the 12 months preceding the interviews, participants had seen a physician for preventative reasons (physical exam, pap test, breast exam; when they had not been sick or had not been bothered by a health problem) $(1=$ Yes and $0=$ No).

\section{TABLE 2}

Operationalization of Health Damaging Behaviours

\section{Health Damaging Behaviours}

Variable

Smoking:

A continuous variable that measured the number of cigarettes participants reported smoking per day.

Alcohol consumption: A dummy variable that measured whether participants reported consuming any alcoholic beverages in the 7 days preceding the interviews ( $1=$ Yes and $0=$ No). 
TABLE 3

Operationalization of Treatment-Focused Health Behaviours

Treatment-Focused Health Behaviours

Variable

Prescription medication treatment:

A dummy variable that measured whether, in the 12 months preceding the interviews, participants had sought and obtained necessary prescription medication treatment:

1. Participants who had sought prescriptions when they were required (had gone to a doctor when they were sick or bothered by a health problem) and filled $100 \%$ of their prescriptions and participants who did not require any prescription medications in the year preceding the interviews (had not been sick or bothered by a health problem).

0 . Participants who had filled less than $100 \%$ of their prescriptions and participants who had not seen a physician when they were sick or bothered by a health problem because they thought the doctor would prescribe a medication that they could not afford.

Dental treatment:

A continuous variable that measured the number of times in the 12 months preceding the interviews that participants reported obtaining dental treatment (fillings, extractions, root canals, emergency treatment...).

Medical treatment:

A continuous variable that measured the number of times in the 12 months preceding the interviews that participants reported seeing a doctor because they had been sick or had been bothered by a health problem.

Corresponding to the conceptual definition of health used in the study, both physical and psychological health were measured. Physical health was measured by a series of self-report items that included self-perceived health, medical conditions, symptoms of illness and/or disease, activity limitations, severity of activity limitations, and frequency of activity limitations. Operationalization of the items used to measure physical health is included in Table 4. Previous research findings provide some evidence that self-report appraisals of health reflect more objective measures of physical health, such as clinical observations, disability rates, and mortality rates (Ferraro 1980; Idler and Angel 1990; Idler and Kasl 1991).

In addition to collecting data about any mental health conditions with which participants reported having been diagnosed, the psychological dimension of health was measured with the "psychologi- cal well-being" sub-scale of the Mental Health Inventory (MHI) (Davies et al. 1988). The "psychological well-being" sub-scale comprises 14 items. These items are categorical and they each have six response options. The score for the psychological well-being sub-scale was calculated by summing the ratings of all the items within the sub-scale. Findings from previous research confirm the test-retest reliability, the internal consistency, and the criterion validity of the psychological well-being subscale of the Mental Health Inventory (Veit and Ware 1983; Ware et al. 1984; Ware et al. 1980).

A number of demographic characteristics, including age, gender, marital status, educational attainment, and percentage that participants' gross family income was of the Statistics Canada LICOs, were used as control variables. Age, educational attainment, and proportion that participants' gross family income was of the LICOs were measured as 
TABLE 4

Operationalization of the Physical Dimension of Health

Variable Description of Variable

Self-perceived health status:

An ordinal variable that measured participants' rating of their health (compared to other people their age) as:

1. Poor

2. Fair

3. Good

4. Very good

5. Excellent

Medical conditions:

A continuous variable that measured the total number of medical conditions participants reported.

Symptoms of illness and/or disease: A continuous variable that measured the total number of symptoms of illness and/or disease that participants reported.

Activity limitations:

A dummy variable that measured whether participants reported experiencing activity limitations associated with medical conditions and/or symptoms of illness and/or disease ( $1=$ Yes and $0=$ No).

Severity of activity limitations: $\quad$ An ordinal variable that measured the degree to which participants' activities were limited by medical conditions and/or symptoms of illness and/or disease:

1. Activities not limited

2. Somewhat limited

3. Limited quite a bit.

4. Limited a great deal/completely limited.

Frequency of activity limitations: An ordinal variable that measured the frequency with which participants experienced activity limitations due to medical conditions and/or symptoms of illness and/or disease:

1. Activities not limited

2. A few times per month

3. $1-6$ times per week

4. Every day.

continuous variables, and gender was coded as a dichotomous variable $(1=$ female and $0=$ male $)$. Similarly, marital status was coded into four dichotomous variables reflecting whether respondents were single (never-married), married (including commonlaw), divorced/separated, or widowed.

\section{Research Procedures}

Data were collected during face-to-face interviews, which were led by a standardized interview guide. The interview guide included questions about demographic characteristics, a variety of health behav- iours, and participants' reported health. Interviews took up to one hour to complete.

\section{Data Analysis}

First, descriptive statistics were used to characterize participants on basic demographic data, their reported health behaviours, and their reported health. For continuously measured variables, independent t-tests were used to compare the demographic characteristics, the health behaviours, and the health of the group of participants living in families receiving social assistance with the group of participants 
living in working poor families. For categorical variables, cross-tabulations, and chi-square tests were used to compare the two groups. An alpha level of no higher than .05 was considered acceptable to establish statistical significance of the findings from both the t-tests and chi-square tests.

Second, seven separate path analyses were used to explore the relationship that poverty status has with both the health behaviours engaged in by people living in poor families and the health of these individuals. Each path analysis corresponded to one of the seven variables that was used to measure health. Path analysis is a method of investigating sequential relationships among quantitative variables (Bohrnstedt and Knoke 1988). Figure 1 depicts the model of the relationships among poverty status, health behaviours, and health that were explored with path analysis.

Employing a series of linear multiple regression equations, path analysis allowed for the estimation of the sign and the magnitude of the relationships shown in Figure 1. Moreover, path analysis allowed for the investigation of the direct and indirect relationships between poverty status and the health of individuals living in poor families (Asher 1983;

FIGURE 1

Hypothesized Relationship Among Poverty Status,

Health Behaviours, and Health

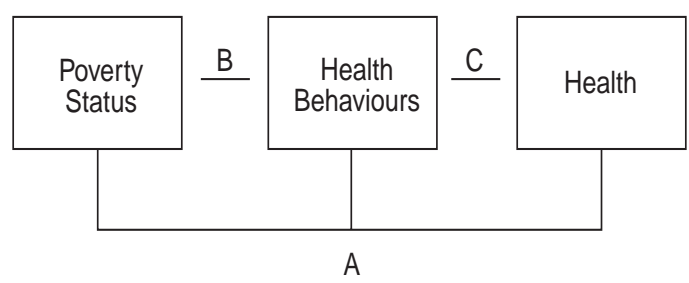

A: Direct relationship between poverty status and health.

B: Direct relationship between poverty status and health behaviours.

C: Direct relationship between health behaviours and health.
Tabachnick and Fidell 1989). A direct relationship is a connecting path between two variables without a mediating variable (Bohrnstedt and Knoke 1988). The paths between poverty status and health (A in Figure 1), poverty status and health behaviours (B in Figure 1), and health behaviours and health $(\mathrm{C}$ in Figure 1) are all direct relationships. The indirect relationship in Figure 1 is the compound path connecting poverty status and health through health behaviours as the mediating variables. The indirect relationships between poverty status and the seven measures of health were calculated by multiplying the path coefficients for the direct relationships between poverty status and health behaviours (B in Figure 1) with the path coefficients for the direct relationships between health behaviours and the variables used to measure health ( $\mathrm{C}$ in Figure 1).

The path models were constructed with two sets of linear multiple regression equations. ${ }^{6}$ In the first set of equations, engagement in health behaviours was estimated as a function of poverty status and the control variables. In the second set of equations, each measure of health was estimated as a function of poverty status, the health behaviours, and the control variables. Hence, the models are assumed to be block recursive in nature.

\section{REsUlTs}

\section{Sample}

The sample consisted of 130 people ranging in age from 17 to 59 years. For the 12 months preceding the interviews, 76 (58.5 percent) of the participants had been living in families receiving social assistance along with comprehensive health care benefits and 54 (41.5 percent) had been living in working poor families that did not have comprehensive health care benefits. Demographic characteristics of the sample are summarized in Appendix Tables 1 and 2. The findings show statistically significant differences between the social assistance and working poor groups with respect to age, educational attainment, marital status, and percentage that gross 
family incomes were of the Statistics Canada LICOs. These differences emphasized the need to control for these demographic variables in the multivariate analyses of the relationships among poverty status, health behaviours, and health.

Comparison of the demographic characteristics of the sample with Statistics Canada data (Oderkirk 1992; Ross et al. 1994; Statistics Canada 1992b) shows the sample from the current study to be representative of relevant populations of poor Canadians with respect to marital status, the number of dependent children per family, and educational attainment. The social assistance sub-group was also representative with respect to gender distribution. On the other hand, women and single-earner families were over-represented in the working poor sub-group.

\section{Health Behaviours and Health}

Findings from the independent t-tests and crosstabulations that were used to compare participants living in families receiving social assistance and participants living in working poor families with respect to health behaviours indicate that there were no statistically significant differences between the two groups with respect to hours of sleep, preventative dental care, preventative medical care, smoking, alcohol consumption, and dental treatment. On the other hand, there were statistically significant differences with respect to exercise, home dental care, medical treatment, and prescription medication treatment (See Appendix Tables 3 and 4). Results show that social assistance participants exercised more often, sought medical treatment more frequently, and were more likely to seek and obtain necessary prescription medication treatment than were their working poor counterparts. In addition, the findings show that participants living in working poor families reported brushing their teeth more frequently than did social assistance participants.

Results from the independent t-tests and the cross-tabulations that were used to compare the health of working poor participants and the health of social assistance participants are shown in Ap- pendix $\mathrm{T}$ ables 5 to 7 . Findings about self-perceived health status, medical conditions, symptoms of illness and/or disease, and activity limitations indicate that participants living in working poor families were healthier than were those living in families receiving social assistance. However, there was no statistically significant difference in the Mental Health Inventory scores between the two groups.

\section{Relationships Among Poverty Status, Health Behaviours, and Health}

Path models corresponding to each measure of health are presented in Figures 2 to 8. The decomposition of the direct, indirect, and net relationships between poverty status and health are presented underneath each path model. The variables used to measure health behaviours were included in the models only if the path coefficients were statistically significant at a level of .05 or less.

Poverty status was not significantly related to participants' engagement in health promoting and health damaging behaviours, with the exception of the relationship between poverty status and home dental care. Working poor participants tended to brush their teeth more frequently than did social assistance participants. In addition, there were few statistically significant relationships between health promoting and health damaging behaviours and any of the seven measures of health. Here exceptions included the relationships between sleep and both MHI scores and the total number of symptoms reported by participants. Those who slept more hours per night had higher MHI scores (Figure 5) and reported fewer symptoms (Figure 4). Another exception was the relationship between exercise and the number of symptoms. Those who exercised more reported a greater number of symptoms (Figure 4). Because most of the health promoting and health damaging behaviours contribute little to explaining the relationship between poverty status and health, they will not be discussed further. Only the health promoting and health damaging behaviour variables that were statistically significant at a level of .05 or less were included in the path model diagrams. 
The majority of the path models (Figures 2, 3, 4, 6 , and 8) show that poverty status had direct, independent relationships with five of the health measures. That is, compared to participants living in working poor families, those living in families receiving social assistance had lower ratings of selfperceived health status, reported greater numbers of medical conditions, experienced greater numbers of symptoms of illness and/or disease, had a greater likelihood of experiencing activity limitations, and experienced activity limitations more often.

Not only do the path models indicate that poverty status was directly associated with the health of participants, but Figures 2 to 8 also show that poverty status had indirect relationships with each measure of health through its relationships with two of the treatment-focused health behaviours. Even though the indirect effects of the relationships between poverty status and the health measures were relatively small, they enhance understanding of the manner in which poverty status is related to health. They are especially informative for the purposes of understanding the relationship between some social assistance and health care policies and the health status of people living in poor families.

One of the indirect relationships between poverty status and the health measures was through the medical treatment variable. The path models show that participants living in families receiving social assistance received medical treatment more often than did participants living in working poor families. And, obtaining medical treatment more often was associated with being less healthy. That is, receipt of medical treatment was associated with lower self-perceived health status, greater numbers of medical conditions, greater numbers of symptoms, lower Mental Health Inventory scores, increased likelihood of experiencing activity limitations, more severe activity limitations, and more frequent activity limitations.

It should be noted that, typical of studies that employ cross-sectional designs, these results do not demonstrate causal relationships among poverty status, use of medical treatment, and health. And, at least two interpretations of the results are possible. One interpretation suggests that people living in families receiving social assistance are less healthy than are people living in working poor families because people living in families receiving social assistance tend to receive medical treatment more frequently than do their working poor counterparts. According to this interpretation, medical treatment causes poor health. A more intuitively appealing interpretation is that the causal relationship runs in the opposite direction. That is, those participants in the sample who were less healthy tended to live in families receiving social assistance, and, because they were less healthy than their working poor counterparts, they tended to obtain medical treatment more often than did participants living in working poor families. According to the latter interpretation, health may have influenced the poverty status of participants, and the health of participants likely influenced the frequency with which they used medical treatment.

The prescription medication variable showed another indirect relationship between poverty status and the reported health of participants. The path models indicate that participants living in working poor families were less likely than their social assistance counterparts to have sought and obtained necessary prescription medication treatment. Failure to seek and obtain necessary prescription medication treatment was, in turn, associated with lower ratings of self-perceived health status, greater numbers of medical conditions, greater numbers of symptoms, lower MHI scores, greater likelihood of experiencing activity limitations, more severe activity limitations, and more frequent activity limitations. Not only do these results confirm earlier findings showing that people living in poverty often do not obtain treatment services for which they do not have benefits (Brand et al. 1977; Family Service Association of Edmonton and Income Security Action Committee 1991), but they also provide evidence that failure to obtain some treatment services 
that are not covered by comprehensive health care benefits is negatively associated with the health of people living in poor families.

Examination of the direct, indirect, and net relationships between poverty status and each of the variables used to measure health enhances understanding of the relationships between poverty status and the health measures. Poverty status was shown to have negative indirect relationships with medical conditions (Figure 3), symptoms of illness and/or disease (Figure 4), likelihood of experiencing activity limitations (Figure 6), and frequency of activity limitations (Figure 8), through the prescription medication treatment variable. However, the direct relationships that poverty status had with each of these four measures of health and the indirect relationships it had through medical treatment were positive and of greater magnitude than the indirect relationships through the prescription medication treatment variable. Consequently, the net relationships between poverty status and medical conditions, symptoms, likelihood of experiencing activity limitations, and frequency of activity limitations were positive. The net relationships suggest that, in general, people living in families receiving social assistance have greater numbers of medical conditions, greater numbers of symptoms of illness and/or disease, are more likely to experience activity limitations, and experience more frequent activity limitations than do their working poor counterparts except when people living in working poor families fail to seek and obtain necessary prescription medication treatment. The negative indirect relationships provide evidence that when individuals living in working poor families fail to seek and obtain necessary prescription medication treatment, they experience more medical conditions, report more symptoms, are more likely to experience activity limitations, and experience activity limitations more frequently than people living in families receiving social assistance.

Figure 7 and its accompanying decomposition table show that, while poverty status was not directly related to severity of activity limitations, it was indirectly related to severity of activity limitations through its relationships with the medical treatment and prescription medication variables. Because the positive indirect relationship through the medical treatment variable was greater in magnitude than the negative indirect relationship through the prescription medication variable, the net relationship between poverty status and severity of activity limitations was positive. Once again, the net relationship suggests that people living in families receiving social assistance experience more severe activity limitations than their working poor counterparts, except when the working poor fail to seek and obtain necessary prescription medication treatment. The negative indirect relationship provides evidence that when individuals living in working poor families fail to seek and obtain necessary prescription medication treatment, the severity of their activity limitations is greater than it is for people living in families that receive social assistance.

The decomposition table presented with Figure 2 shows that poverty status had a positive indirect relationship with participants' self-perceived health status through the prescription medication treatment variable. In contrast, the indirect relationship between poverty status and self-perceived health status through medical treatment and the direct relationship that poverty status had with self-perceived health status were both negative and of greater magnitude than the positive indirect relationship through the prescription medication variable. As such, the net relationship between poverty status and selfperceived health status was negative. This suggests that the self-perceived health status of people living in families receiving social assistance is, in general, less than that of people living in working poor families. The indirect positive relationship through the prescription medication treatment variable suggests that the self-perceived health status of people living in working poor families is less than that of their social assistance counterparts when they fail to seek and obtain necessary prescription medication treatment. 
Lastly, in contrast to the net relationships between poverty status and the measures of health discussed above, the decomposition table accompanying Figure 5 indicates that the net relationship between poverty status and Mental Health Inventory scores was positive. Participants living in families receiving social assistance had higher MHI scores than did working poor participants. Findings show that the positive indirect relationship that poverty status had through its relationship with the prescription medication treatment variable was of greater magnitude than the negative indirect relationship between poverty status and MHI scores through medical treatment.

FiguRE 2

Path Model of Factors Related to Self-Perceived Health Status ${ }^{\mathrm{a}}$

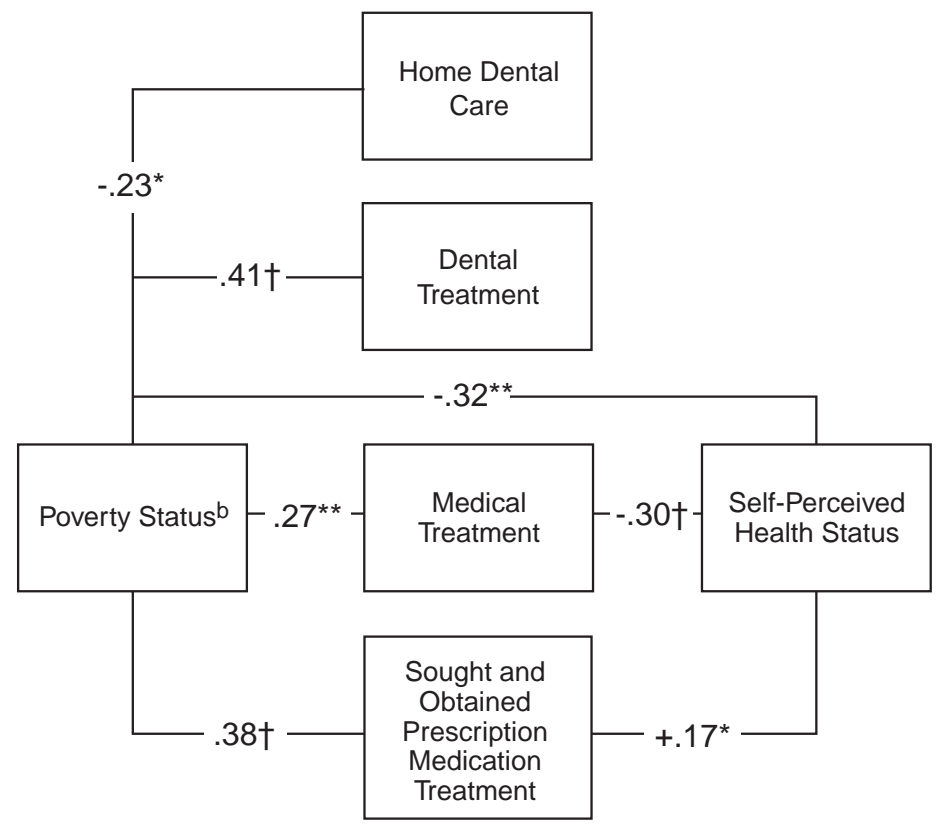

Only paths significant at .05 or less included

aRelationship established while controlling for age, educational attainment, gender, marital status, and percentage that family incomes were of the LICOs.

${ }^{b}$ Coded as $1=$ living in family receiving social assistance and $0=$ living in working poor family.

${ }^{*} p \leq .05$ (1-tail) ${ }^{* *} p \leq .01$ (1-tail) $\quad t p \leq .001$ (1-tail)

Decomposition of the Relationship Between Poverty Status and Self-Perceived Health Status

\begin{tabular}{lccc}
\hline Variable & Direct Relationship & Indirect Relationships & Net Relationship \\
\hline Poverty Status & -.32 & $-.08^{\mathrm{a}}$ & \\
& & $.06^{\mathrm{b}}$ & -.34 \\
\hline
\end{tabular}

aThrough the medical treatment variable.

'Through the variable used to measure the proportion of participants who sought and obtained necessary prescription medication treatment. 


\section{FIGURE 3}

Path Model of Factors Related to Number of Medical Conditions ${ }^{\mathrm{a}}$

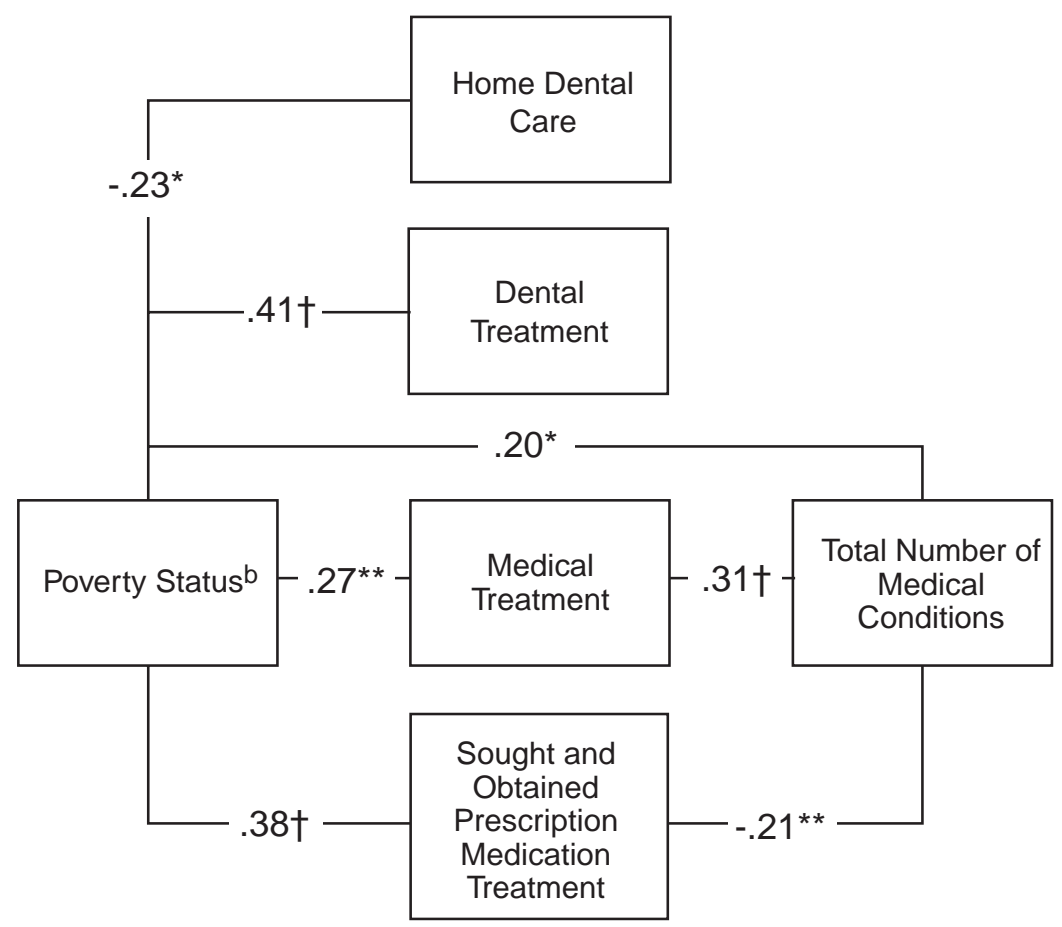

Only paths significant at .05 or less included

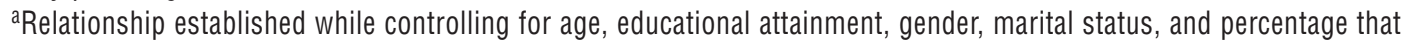
family incomes were of the LICOs.

${ }^{b}$ Coded as $1=$ living in family receiving social assistance and $0=$ living in working poor family.

${ }^{*} p \leq .05$ (1-tail) $\quad{ }^{* *} p \leq .01$ (1-tail) $\quad t p \leq .001$ (1-tail)

Decomposition of the Relationship Between Poverty Status and Total Number of Medical Conditions

\begin{tabular}{lccc}
\hline Variable & Direct Relationship & Indirect Relationships & Net Relationship \\
\hline Poverty Status & .20 & $.08^{\mathrm{a}}$ & \\
& & $-.08^{\mathrm{b}}$ & .20 \\
\hline
\end{tabular}

aThrough the medical treatment variable.

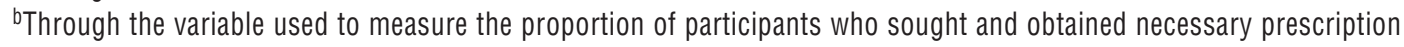
medication treatment. 


\section{FIGURE 4}

Path Model of Factors Related to Total Number of Symptoms ${ }^{\mathrm{a}}$

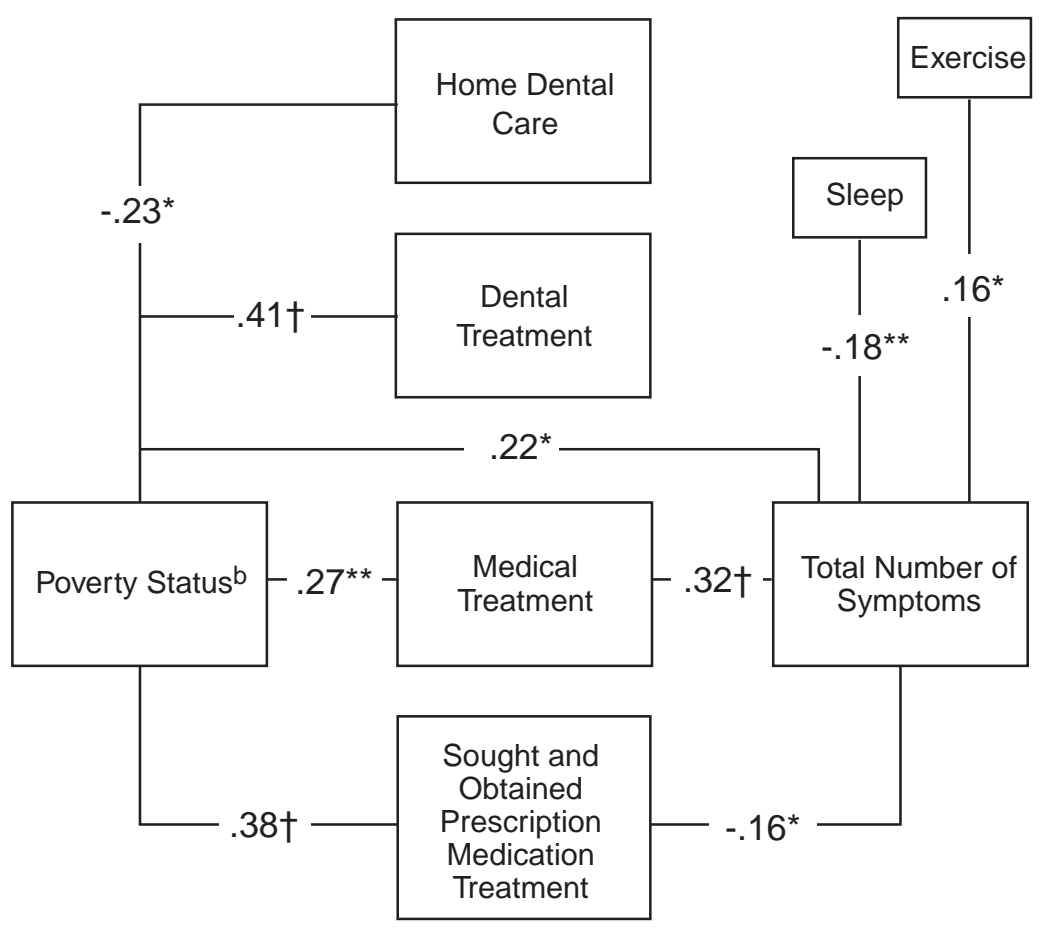

Only paths significant at .05 or less included

aRelationship established while controlling for age, educational attainment, gender, marital status, and percentage that family incomes were of the LICOs.

${ }^{b}$ Coded as $1=$ living in family receiving social assistance and $0=$ living in working poor family.

${ }^{*} p \leq .05$ (1-tail) $\quad{ }^{* *} p \leq .01$ (1-tail) $\quad t p \leq .001$ (1-tail)

Decomposition of the Relationship Between Poverty Status and Total Number of Symptoms Related to IIIness and/or Disease

\begin{tabular}{lccc}
\hline Variable & Direct Relationships & Indirect Relationships & Net Relationships \\
\hline Poverty Status & .22 & $.09^{\mathrm{a}}$ & .25 \\
& & $-.06^{\mathrm{b}}$ & .16 \\
Exercise & .16 & & -.18 \\
Sleep & -.18 & &
\end{tabular}

aThrough the medical treatment variable.

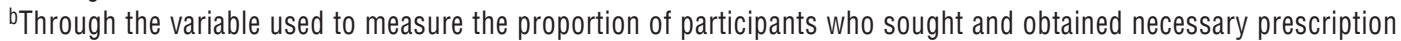
medication treatment. 


\section{FIGURE 5}

Path Model of Factors Related to Mental Health Inventory (MHI) Score ${ }^{a}$

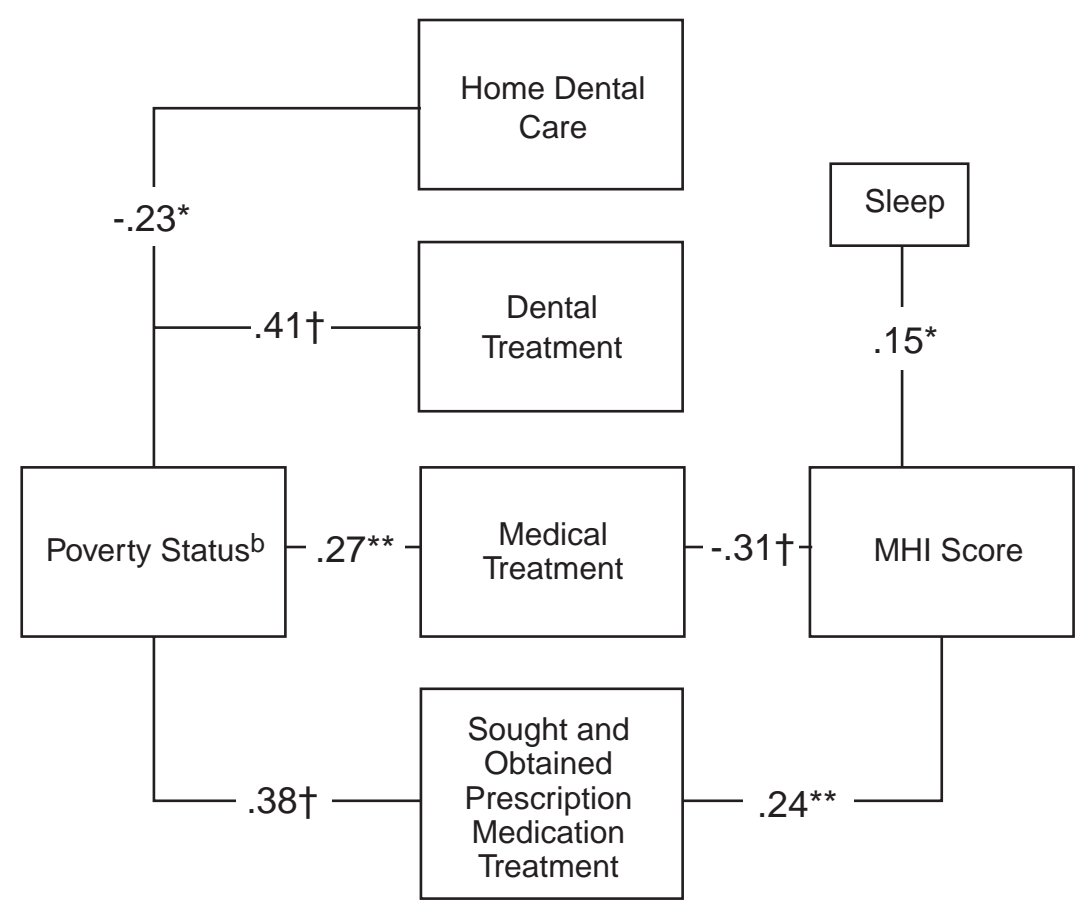

Only paths significant at .05 or less included

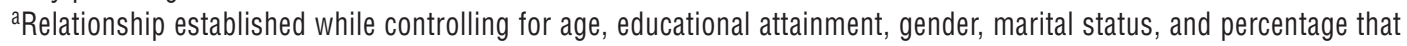
family incomes were of the LICOs.

${ }^{b}$ Coded as $1=$ living in family receiving social assistance and $0=$ living in working poor family.

${ }^{*} p \leq .05$ (1-tail) ${ }^{* *} p \leq .01$ (1-tail) $\quad t p \leq .001$ (1-tail)

Decomposition of the Relationship Between Poverty Status and Mental Health Inventory (MHI) Score

\begin{tabular}{lccc}
\hline Variable & Direct Relationship & Indirect Relationships & Net Relationships \\
\hline Poverty Status & -- & $-.08^{\mathrm{a}}$ & \\
& -- & $.09^{\mathrm{b}}$ & .01 \\
Sleep & .15 & & .15 \\
\hline
\end{tabular}

aThrough the medical treatment variable.

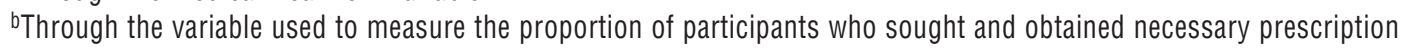
medication treatment. 


\section{FIGURE 6}

Path Model of Factors Related to Activity Limitations ${ }^{\mathrm{a}}$

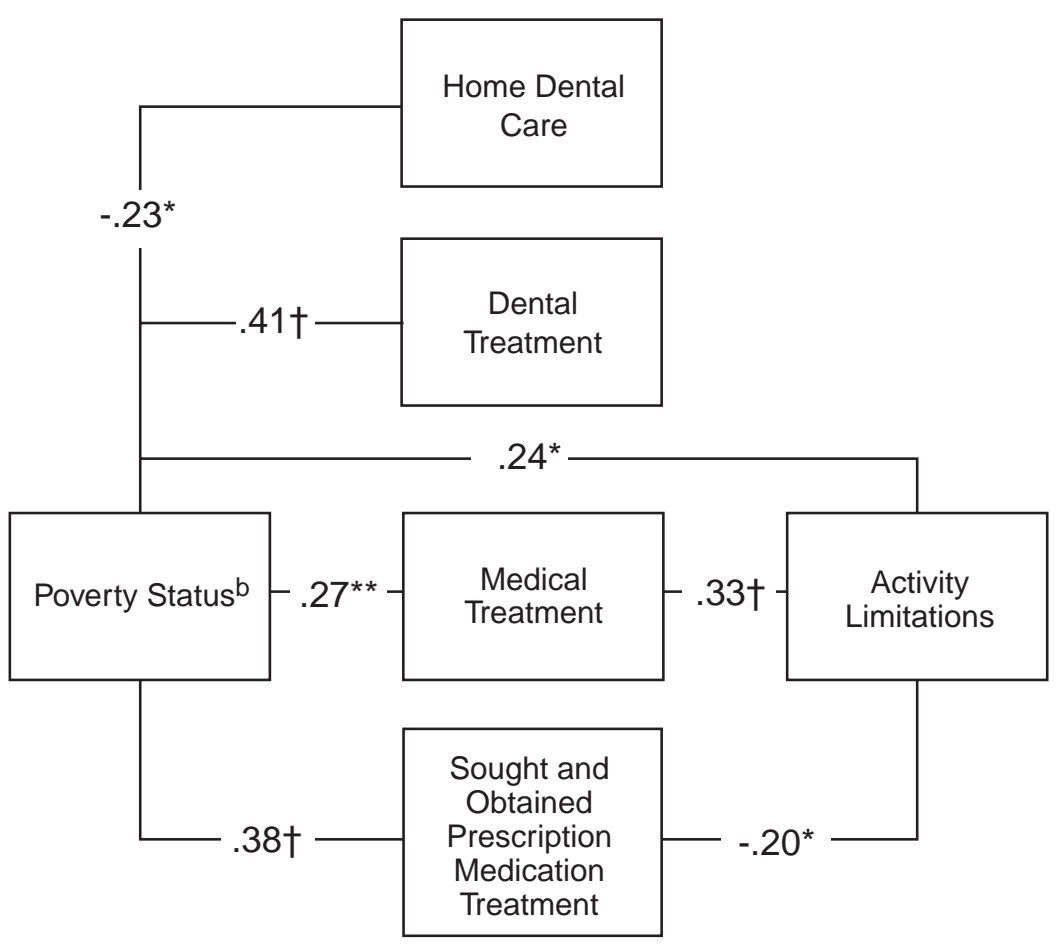

Only paths significant at .05 or less included

aRelationship established while controlling for age, educational attainment, gender, marital status, and percentage that family incomes were of the LICOs.

${ }^{b}$ Coded as $1=$ living in family receiving social assistance and $0=$ living in working poor family.

${ }^{*} p \leq .05$ (1-tail) ${ }^{* *} p \leq .01$ (1-tail) $\quad t p \leq .001$ (1-tail)

Decomposition of the Relationship Between Poverty Status and Activity Limitations

\begin{tabular}{lccc}
\hline Variable & Direct Relationship & Indirect Relationships & Net Relationship \\
\hline Poverty Status & .24 & $-.09^{\mathrm{a}}$ & \\
& & $-.08^{\mathrm{b}}$ & .25 \\
\hline
\end{tabular}

aThrough the medical treatment variable.

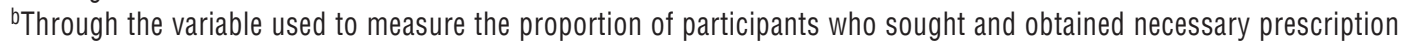
medication treatment. 


\section{FIGURE 7}

Path Model of Factors Related to Severity of Activity Limitations ${ }^{\mathrm{a}}$

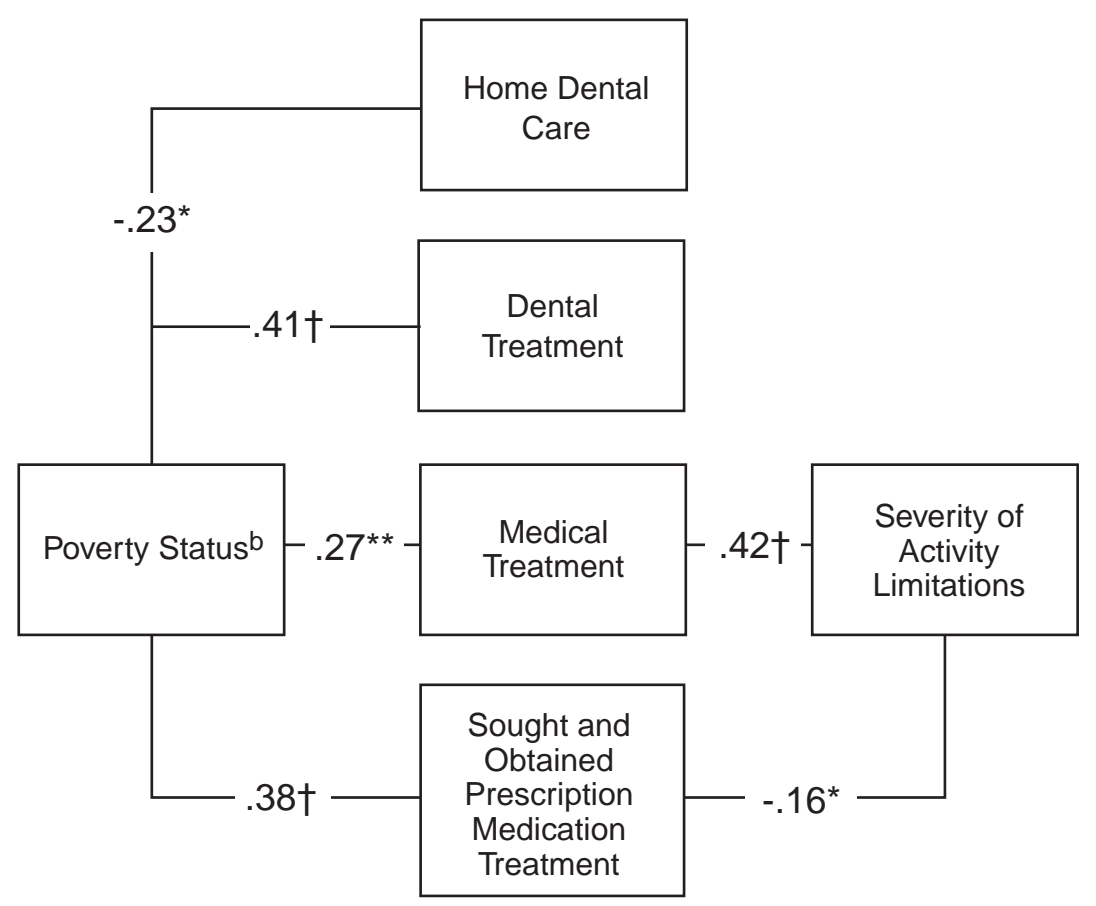

Only paths significant at .05 or less included

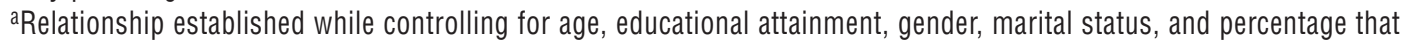
family incomes were of the LICOs.

${ }^{b}$ Coded as $1=$ living in family receiving social assistance and $0=$ living in working poor family.

${ }^{*} p \leq .05$ (1-tail) ${ }^{* *} p \leq .01$ (1-tail) $\quad t p \leq .001$ (1-tail)

Decomposition of the Relationship Between Poverty Status and Severity of Activity Limitations

\begin{tabular}{lccc}
\hline Variable & Direct Relationship & Indirect Relationships & Net Relationship \\
\hline Poverty Status & -- & $.11^{\mathrm{a}}$ & \\
& & $-.06^{\mathrm{b}}$ & .05 \\
\hline
\end{tabular}

aThrough the medical treatment variable.

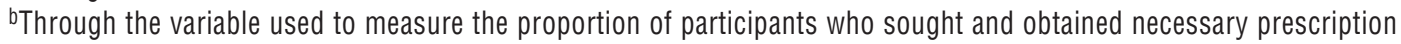
medication treatment. 


\section{FIGURE 8}

Path Model of Factors Related to Frequency of Activity Limitations ${ }^{\mathrm{a}}$

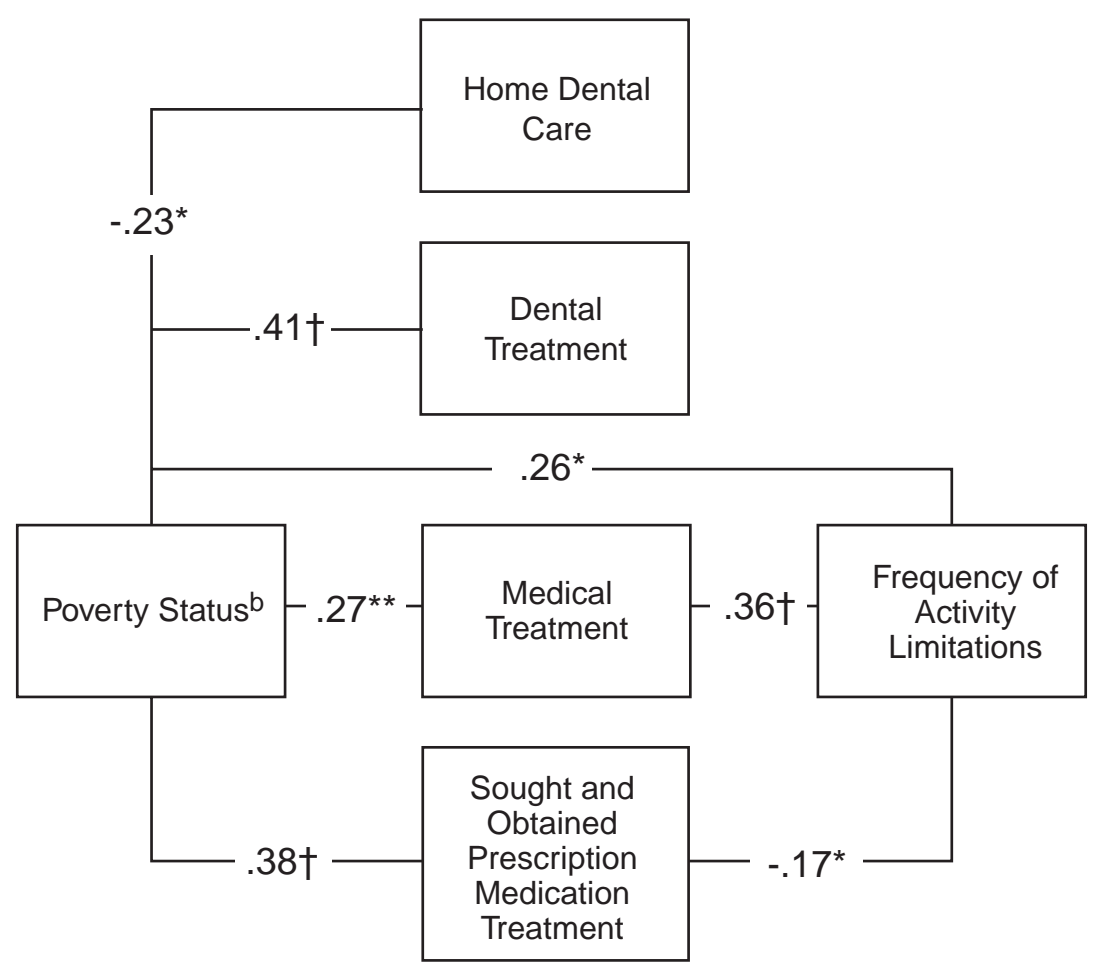

Only paths significant at .05 or less included

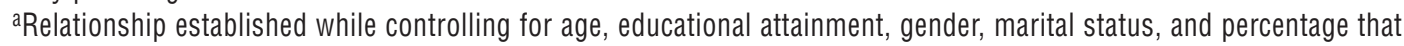
family incomes were of the LICOs.

${ }^{b}$ Coded as $1=$ living in family receiving social assistance and $0=$ living in working poor family.

${ }^{*} p \leq .05$ (1-tail) ${ }^{* *} p \leq .01$ (1-tail) $\quad t p \leq .001$ (1-tail)

Decomposition of the Relationship Between Poverty Status and Frequency of Activity Limitations

\begin{tabular}{lccc}
\hline Variable & Direct Relationship & Indirect Relationships & Net Relationship \\
\hline Poverty Status & .26 & $.10^{\mathrm{a}}$ & \\
& & $-.06^{\mathrm{b}}$ & .30 \\
\hline
\end{tabular}

aThrough the medical treatment variable.

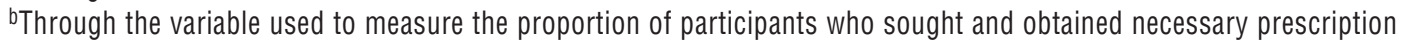
medication treatment. 


\section{Summary And Conclusions}

Researchers have paid little attention to people living in working poor families and those living in families receiving social assistance. The findings presented in this paper enhance knowledge about the impact that some social assistance and health care policies have on the utilization of health care services by people living in these two groups of poor families, and so are significant.

Results from the path analyses indicate that poverty status was differentially related to the health of study participants. More specifically, the findings indicate that participants living in working poor families were, in general, healthier than were participants living in families receiving social assistance. Thus, referring back to the definition of health being used in this study, these findings suggest that people living in working poor families generally tend to have greater opportunities to make choices, lead socially and economically productive lives, and gain satisfaction from living than do people living in families that receive social assistance. However, results also suggest that people living in working poor families may be less healthy than their social assistance counterparts when the working poor's lack of comprehensive health care benefits prevents them from accessing necessary medical treatment.
Similar to previous research findings (Brand et al. 1977; Family Service Association of Edmonton and Income Security Action Committee 1991), results from the study reported here suggest that people living in working poor families that do not have comprehensive health care benefits are less likely than those who live in families receiving social assistance to obtain treatment services beyond those that are provided by Alberta Health Care. Moreover, it seems that when people living in working poor families do not seek and obtain necessary prescription medication treatment, they are less healthy than are people living in families receiving social assistance. As a result, their opportunity to make choices and to lead socially and economically productive lives is diminished. Figure 9 summarizes the relative health of people living in families receiving social assistance and people living in working poor families. Working poor participants who sought and obtained necessary prescription medication treatment were relatively healthier than social assistance participants who were, in turn, relatively healthier than working poor participants who failed to seek and obtain necessary prescription medication treatment.

One of the major differences between the two sub-groups in the current study was the differential availability of comprehensive health care benefits. Thus, it seems reasonable to suggest that the findings

\section{FIGURE 9}

The Relative Health Status of Study Participants

Health
Status $\quad \begin{aligned} & \text { Best } \\ & \text { Worst } \\ & \text { and obtained necessary prescription } \\ & \text { medication treatment }\end{aligned}$


about the relationships among the availability of comprehensive health care benefits, the utilization of treatment services, and health can be generalized to other groups of Canadians living in poverty who differ with respect to their comprehensive health care coverage. In other words, findings from this study provide some evidence that access to prescription medication treatment is one factor that is related to the health of people living in poverty.

The findings from this study have three important implications for social assistance and health care policy in Alberta and other provinces whose recent policy initiatives have focussed on significant reductions in expenditures on public services. First, study results are particularly noteworthy in light of both recent cutbacks to the health care benefits provided to social assistance recipients in Alberta and simultaneous policy initiatives to move social assistance recipients into the workforce. Health care benefits available to social assistance recipients have been the target of some recent spending cutbacks in $\mathrm{Al}-$ berta. Since the fall of 1993, there have been reductions to the dental benefits, prescription medication benefits, and optical benefits available to social assistance recipients (Alberta Dental Services Corporation 1994; Alberta Family and Social Services 1994; Ohler 1994). Concurrently, much energy is being devoted to moving social assistance recipients into the workforce. Recent policy initiatives have concentrated on job training, the creation of job corps, employment preparation initiatives, and education/training initiatives (Alberta Family and Social Services 1993; Arnold 1995). Results from this study suggest that policies that reduce comprehensive health care benefits available to social assistance recipients are likely to undermine the success of programs intended to move social assistance recipients into the workforce. Specifically, reductions to prescription medication benefits can be expected to negatively affect the health, and thus the employability, of social assistance recipients, a group of people whose health and employability is already limited by their poverty status. Further reductions in the health status of social assistance recipients, will, in turn, hinder their ability to move into the workforce. Instead of cutting health care benefits available to social assistance recipients, findings from this study underscore the need to invest in comprehensive health care benefits for $\mathrm{Ca}$ nadians receiving social assistance.

Secondly, findings from the current study emphasize the need to provide transitional health care benefits to people once they leave social assistance and become employed. Most often when people move from social assistance to the labour force, they acquire low-paying jobs that seldom provide comprehensive health care benefits (Alberta Family and Social Services 1993; Gunderson and Muszynski 1990). Study results suggest that the provision of prescription medication benefits to these people will enhance their health and simultaneously enhance their ability to fulfil their employment responsibilities.

Lastly, to the extent that the results of this study can be generalized, they can also help inform policy affecting others living in poverty, such as the working poor who have never received social assistance, people receiving unemployment insurance, and people receiving student loans. The findings from this study emphasize the need for investing in the development of policies and programs that ensure the provision of prescription medication benefits to all those living in poverty, regardless of their poverty status. In light of public concern about deficits and debts, the suggestion to implement such policies is likely to be opposed with concerns about excessive cost. However, findings from this study suggest that, in the long run, the health of poor Albertans will be enhanced by such policies. Better health among Albertans living in poverty will, in turn, positively affect their life satisfaction, employability, and work productivity, which will provide both employees and employers with a competitive advantage in our increasingly globalized economy. In addition, and of particular relevance in the current socioeconomic and political environment, which is characterized by rhetoric about disparities between program demands and available resources (McQuaig 1995), 
better health among Albertans living in poor families could ultimately decrease the need for public expenditures on treatment-focused health care.

\section{Notes}

Financial support for this study by a research grant (\#6609-1963-55) from the National Health Research and Development Program of Health Canada is gratefully acknowledged.

${ }^{1}$ For the purposes of this study, poverty was conceptualized as the relative deprivation of material resources that are necessary to meet basic needs and a standard of living that is expected by the society within which one lives (Forum Director's Group, National Forum on Family Security 1993; Ross et al. 1994).

${ }^{2}$ Families are defined here as couples living with children, couples living with other relatives, couples only, single parents living with their children, and siblings living together in the same household (Ross et al. 1994).

${ }^{3}$ The Centre for International Statistics, Canadian Council on Social Development and Ross et al. used the Statistics Canada low income cut-offs (LICOs) to determine poverty rates. Although Statistics Canada does not describe the LICOs as poverty lines, the measures are viewed as such by most social policy observers (Murphy 1993; Ross et al. 1994).

${ }^{4}$ Alberta Health Care provides physician and hospital services. It does not provide dental care or prescription medications. Families that receive social assistance are provided with premium-free Alberta Health Care coverage (Alberta Family and Social Services 1994). In order to assist working poor families meet the requirement that all Albertans have Alberta Health Care coverage, premium subsidies are available.

${ }^{5}$ The LICOs are income levels at which families, differentiated by family size and the population of the community within which they live, spend 20 percent more on basic needs than the average amount spent by Canadian families. Basic needs are identified as food, shelter, and clothing. The average proportion of income currently believed to be spent on basic needs has been estimated by Statistics Canada to be 34.7 percent. Thus, with the addition of 20 percentage points, the low income standard is set at 54.7 percent. That is, families whose expenditures on necessities exceed 54.7 percent of their gross income, are living below the LICOs (Ross and Shillington 1989; Statistics Canada 1992a). Data for the study discussed here were collected from August 1994 to March 1995. Therefore, the 1992 LICOs were adjusted to reflect the 1993 inflation rate of 1.8 percent and the average inflation rate of the first six months of 1994 of .28 percent (Statistics Canada 1994).

${ }^{6}$ Four of the health behaviour variables were dichotomous. These variables were those that measured whether participants had consumed alcohol in the 7 days preceding the interviews, whether participants had received preventative medical care in the past 12 months, whether participants had received preventative dental care in the past year, and whether participants had sought and obtained necessary prescription medication treatment in the 12 months preceding the interviews. Similarly, the variable used to measure whether participants had activity limitations related to medical conditions and/or symptoms was dichotomous. The regression models in which the dichotomous variables were used as dependent variables were analyzed with both multiple regression and logistical regression. The findings from both types of regression analyses yielded almost identical results. As such, and because path analysis employs linear multiple regression equations, the dichotomous variables were used as dependent variables in the linear multiple regression models used to construct the path models.

\section{REFERENCES}

Adams, O. (1993), "Health Status," in Canada's Health Promotion Survey 1990: Technical.Report, ed. T. Stephens and D. Fowler Graham (Ottawa: Supply and Services Canada).

Alberta Dental Service Corporation (1994), Alberta Family and Social Services Dental Benefits Program (Edmonton: Alberta Dental Service Corporation).

Alberta Family and Social Services (1993), Welfare Reform in Alberta (Edmonton: Alberta Family and Social Services).

(1994), One Step at a Time: Supports for Independence (Edmonton: Alberta Family and Social Services). Arnold, T. (1995), "Workfare Set for Year 2000," Calgary Herald, 6 July, p. A1.

Asher, H.B. (1983), Causal Modeling (Newbury Park: Sage). 
Ashton, J. and H. Seymour (1993), "The Setting for a New Public Health," Health and Well-being: A Reader, ed. A. Beattie, M. Gott, L. Jones and M. Sidell (London: The Open University).

Bohrnstedt, G.W. and D. Knoke (1988), Statistics for Social Data Analysis, 2nd ed. (Itasca: F.E. Peacock Publishers).

Brand, F.N., R.T. Smith and P.A. Brand (1977), "Effect of Economic Barriers to Medical Care on Patients' Noncompliance," Public Health Reports 92:165-81.

Centre for International Statistics, Canadian Council on Social Development (1996), Family Poverty Rates, All Families and Families with Children Under 18, Canada and the Provinces, 1993 (On line: http:// www.achilles.net/ council/fs_fam93.html) (Ottawa: CCSD).

Davies, A.R., C.D. Sherbourne, J.R. Peterson, and J.E. Ware (1988), Scoring Manual: Adult Health Status and Patient Satisfaction Measures Used in RAND's Health Insurance Experiment (Santa Monica: RAND Corporation).

Duffy, M.E. (1989), "Determinants of Health Status in Employed Women, Health Values 13(2):50-57.

Epp, J. (1986), Achieving Health for All: A Framework for Health Promotion (Ottawa: Health and Welfare Canada).

Family Service Association of Edmonton and Income Security Action Committee (1991), Working Hard, Living Lean: A Qualitative Study of Working LowIncome Families in Edmonton (Sherwood Park: Holmgren Consulting Group).

Ferraro, K.F. (1980), "Self-Ratings of Health Among the Old and the Old-Old," Journal of Health and Social Behavior 21: 377-83.

Forum Director's Group, National Forum on Family Security (1993), "Keynote Paper," in Family Security in Insecure Times (Ottawa: Canadian Council on Social Development).

Frank, J.W. (1995), "Why 'Population Health'?" Canadian Journal of Public Health 86(3):162-64.

Gunderson, M. and L. Muszynski (1990), Women and Labour Market Poverty (Ottawa: Canadian Advisory Council on the Status of Women).

Hay, D.I. (1988), "Socioeconomic Status and Health Status: A Study of Males in the Canada Health Survey," Social Science and Medicine 27(12):1317-25.

Health Education Unit, World Health Organization (1993), "Life-styles and Health," in Health and Well-being:
A Reader, ed. A. Beattie, M. Gott, L. Jones and M. Sidell (London: The Open University).

Hess, M. (1987), The Working Poor: Their Dilemma and Assistance Through Provincial Income Supplementation Programs (Toronto: Social Assistance Review Committee).

Hirdes, J.P., K.S. Brown, W.F. Forbes, D.S. Vigoda and L. Crawford (1986), "The Association Between Selfreported Income and Perceived Health Based on the Ontario Longitudinal Study of Aging," Canadian Journal on Aging 5(3):189-204.

Idler, E.L. and R.J. Angel (1990), "Self-rated Health and Mortality in the NHANES-I Epidemiologic Followup Study," American Journal of Public Health 80(4): 446-52.

Idler, E.L. and S. Kasl (1991), "Health Perceptions and Survival: Do Global Evaluations of Health Status Really Predict Mortality?" Journal of Gerontology: Social Sciences 46(2): S55-65.

Labonte, R. (1995), "Population Health and Health Promotion: What Do They Have to Say to Each Other? Canadian Journal of Public Health 86(3):165-8.

Mahler, H. (1981), "The Meaning of 'Health for all by the year 2000'," World Health Forum 1(1):5-22.

(1988), "The Battle for Health," World Health Forum 9:143-6.

Manga, P. (1993), "Socio-Economic Inequalities," in Canada's Health Promotion Survey 1990:Technical Report, ed. T. Stephens and D. Fowler Graham (Ottawa: Supply and Services Canada).

McQuaig, L. (1995), Shooting the Hippo: Death by Deficit and Other Canadian Myths (Toronto: Penguin).

Meister, S. (1993), "The Family's Agents: Policy and Nursing," The Nursing of Families: Theory, Research, Education, Practice, ed. S. Feetham, S. Meister, J. Bell and C. Gillis (Newbury Park: Sage).

Milio, N. (1988), Primary Care and the Public's Health (Ottawa: Canadian Public Health Association).

Murphy, J. (1993), "Analyzing the Poverty of Christopher Sarlo," Perception 17(2):19-21.

Oderkirk, J. (1992), "Parent and Children Living with Low Incomes," Canadian Social Trends 27:11-15.

Ohler, S. (1994), "Recipients Can Afford Eye Exams Minister," Calgary Herald, 21 December, p. A8.

Ott, A.F. (1990), "Life Styles, Job Environment and Health Status: Some Empirical Findings from West Germany," Social Science Journal 27(3):339-56.

Roberge, R., J. Berthelot and M. Wolfson (1995), "Health 
and Socio-economic Inequalities," Canadian Social Trends 37:15-19.

Ross, D.P., E.R. Shillington and C. Lochhead (1994), The Canadian Fact Book on Poverty (Ottawa: Canadian Council on Social Development).

Ross, D.P. and R. Shillington (1989), The Canadian Fact Book on Poverty - 1989 (Ottawa: Canadian Council on Social Development).

Segovia, J., R.F. Bartlett and A.C. Edwards (1989), "An Empirical Analysis of the Dimensions of Health Status Measures," Social Science and Medicine 6:761-68.

Siler-Wells, G. (1988), "Public Participation in Community Health," Health Promotion 27(1):7-11.

Statistics Canada (1992a), Income Distributions by Size in Canada (Ottawa: Minister of Industry, Science and Technology).

(1992b), Families: Number, Type, and Structure (Ottawa: Minister of Industry, Science and Technology).

(1994), The Consumer Price Index (Ottawa: Minister of Industry, Science and Technology).

Stevens, P.E. and J.M. Hall (1992), "Applying Critical Theories to Nursing in Communities," Public Health Nursing 9(1):2-9.

Tabachnick, B.G. and L.S. Fiddell (1989), Using Multivariate Statistics, 2nd ed. (New York: Harper Collins).

Tanner, E.K.W. (1991), "Assessment of a Health-Promotive Lifestyle," Nursing Clinics of North America 26(4):845-54.
Veit, C.T. and J.E. Ware (1983), "The Structure of Psychological Distress and Well-being in General Populations," Journal of Consulting and Clinical Psychology 51(5):730-42.

Ware, J.E., A. Davies-Avery and R.H. Brook (1980), Conceptualization and Measurement of Health for Adults in the Health Insurance Study. Vol. 6, Analysis of Relationships Among Health Status Measures (Santa Monica: Rand Corporation).

Ware, J.E., W.G. Manning, N. Duan, K.B. Wells and J.P. Newhouse (1984), "Health Status and the Use of Outpatient Mental Health Services," American Psychologist 39(10):1090-1100.

Wilkins, R. (1988), Special Study on the Socially and Economically Disadvantaged (Ottawa: Supply and Services Canada).

Wilkins, R., O. Adams and A. Brancker (1989), "Changes in Mortality by Income in Urban Canada from 1971 to 1986," Health Reports 1(2):137-74.

Wilkins, R., G.J. Sherman and P.A.F. Best (1991), "Birth Outcomes and Infant Mortality by Income in Urban Canada," Health Reports 3(1):7-31.

Williamson, D.L. and J.E. Fast (1993), "The Health Status of Working Poor Families and Families Who Are Eligible for Social Assistance," Paper presented at the International Conference on Community Health Nursing Research, Edmonton, Alberta.

World Health Organization (1987), "Ottawa Charter for Health Promotion," Health Promotion, 1(4):iii-v. 
Appendix Table 1

Means (Standard Deviations) for Continuous Demographic Variables

\begin{tabular}{lcccc}
\hline & Sample & Social Assistance & Working Poor & T-Value \\
\hline Age (years) & 33.9 & 32.5 & 35.9 & $2.16^{*}$ \\
& $(9.1)$ & $(9.3)$ & $(8.5)$ & \\
Number of children living at home & 2.1 & 2.0 & 2.2 & .95 \\
& $(1.2)$ & $(1.3)$ & $(1.2)$ & \\
Years of education & 11.4 & 10.5 & 12.7 & $3.69 \dagger$ \\
& $(3.3)$ & $(2.5)$ & $(3.8)$ & \\
Percentage that gross family income & & & & \\
was of LICOs (\%) & 57.6 & 52.7 & 64.6 & $4.32 \dagger$ \\
& $(15.3)$ & $(11.1)$ & $(17.6)$ & \\
\hline
\end{tabular}

${ }^{*} p \leq .05$ (2-tail) $\quad t p \leq .001$ (2-tail)

Appendix Table 2

Proportion of Sample by Gender, Marital Status, and Level of Education

\begin{tabular}{|c|c|c|c|c|}
\hline & Sample & Social Assistance & Working Poor & Chi-Square \\
\hline \multicolumn{5}{|l|}{ Gender } \\
\hline Females & $81.5(\underline{n}=106)$ & $85.5(\underline{n}=65)$ & $75.9(\underline{n}=41)$ & \\
\hline Males & $18.5(\underline{n}=24)$ & $14.5(\underline{\underline{n}}=11)$ & $24.1(\underline{n}=13)$ & 1.9 \\
\hline \multicolumn{5}{|l|}{ Marital status } \\
\hline Single (never married) & $26.9(\underline{n}=35)$ & $38.2(\underline{n}=29)$ & $11.1(\underline{n}=6)$ & \\
\hline Married/Common-law & $42.3(\underline{n}=55)$ & $23.7(\underline{\underline{n}}=18)$ & $68.5(\underline{\underline{n}}=37)$ & \\
\hline Separated/Divorced & $26.2(\underline{n}=34)$ & $31.6(\underline{\underline{n}}=24)$ & $18.5(\underline{\underline{n}}=10)$ & \\
\hline Widowed & $4.6(\underline{n}=6)$ & $6.6(\underline{n}=5)$ & $1.9(\underline{\mathrm{n}}=1)$ & $27.2 \dagger$ \\
\hline \multicolumn{5}{|l|}{ Level of education } \\
\hline Less than high school & $61.5(\underline{n}=80)$ & $77.6(\mathrm{n}=59)$ & $38.9(\underline{n}=21)$ & \\
\hline High school & $16.2(\underline{n}=21)$ & $10.5(\underline{n}=8)$ & $24.1(\underline{n}=13)$ & \\
\hline Post-secondary diploma & $12.3(\underline{n}=16)$ & $9.2(\underline{n}=7)$ & $16.7(\underline{n}=9)$ & \\
\hline Bachelor's degree & $8.5(\underline{n}=11)$ & $1.3(\mathrm{n}=1)$ & $18.5(\underline{n}=10)$ & \\
\hline Graduate degree & $1.5(\underline{n}=2)$ & $1.3(\underline{n}=1)$ & $1.9(\underline{n}=1)$ & $23.8 \dagger$ \\
\hline
\end{tabular}

$\dagger p \leq .001$ 
Appendix Table 3

Means (Standard Deviations) for Continuous Health Behaviour Variables

\begin{tabular}{lcccc}
\hline & Sample & Social Assistance & Working Poor & T-Value \\
\hline Hours of sleep per 24 hours & 7.15 & 7.15 & 7.15 & -.01 \\
& $(1.8)$ & $(2.0)$ & $(1.5)$ & \\
Exercise & 7.56 & 8.13 & 6.76 & $-1.97^{*}$ \\
& $(3.9)$ & $(3.7)$ & $(4.0)$ & \\
Number of cigarettes smoked per day & 17.1 & 16.5 & 18.2 & .69 \\
& $(9.4)$ & $(9.0)$ & $(10.0)$ & \\
Number of times dental treatment had been & & & & -1.68 \\
obtained in past 12 months & 2.2 & 2.6 & $(2.2)$ & \\
& $(2.6)$ & $(2.7)$ & & \\
Number of times medical treatment had been & & & & \\
obtained in past 12 months & 11.9 & 15.3 & & \\
& $(19.5)$ & $(21.3)$ & & \\
\hline${ }^{*} \mathrm{p} \leq .05$ (2-tail) ${ }^{* *} \mathrm{p} \leq .01$ (2-tail) & & & & \\
\hline \hline
\end{tabular}

Appendix Table 4

Proportions and Chi-Square Values for Categorical Health Behaviour Variables

\begin{tabular}{|c|c|c|c|c|}
\hline & Sample & Social Assistance & Working Poor & Chi-Square \\
\hline \multicolumn{5}{|l|}{ Frequency of teeth brushing } \\
\hline Once a week or less & $17.7(\underline{\mathrm{n}}=23)$ & $26.7(\underline{\mathrm{n}}=20)$ & $5.6(\underline{n}=3)$ & \\
\hline 2 - 6 times a week & $5.4(\underline{n}=7)$ & $5.3(\underline{\underline{n}}=4)$ & $5.6(\underline{n}=3)$ & \\
\hline Once a day & $18.5(\underline{n}=24)$ & $16.0(\underline{n}=12)$ & $22.2(\underline{n}=12)$ & \\
\hline At least twice per day & $57.7(\underline{n}=75)$ & $52.0(\underline{n}=39)$ & $66.7(\underline{\underline{n}}=36)$ & \\
\hline Missing & $.8(\underline{n}=1)$ & $.01(\underline{n}=1)$ & 0 & $9.67^{\star}$ \\
\hline $\begin{array}{l}\text { Had obtained preventative dental care in past } \\
12 \text { months }\end{array}$ & $30.0(\underline{n}=39)$ & $32.9(\underline{n}=25)$ & $25.9(\underline{n}=14)$ & .73 \\
\hline $\begin{array}{l}\text { Had obtained preventative medical care in past } \\
12 \text { months }\end{array}$ & $60.8(\underline{n}=79)$ & $64.5(\underline{n}=49)$ & $55.6(\underline{n}=30)$ & .30 \\
\hline Had consumed alcohol in past 7 days & $25.4(\underline{n}=33)$ & $22.4(\underline{n}=17)$ & $29.6(\underline{n}=16)$ & .88 \\
\hline \multicolumn{5}{|l|}{$\begin{array}{l}\text { Sought and obtained necessary prescription } \\
\text { medication treatment in the } 12 \text { months }\end{array}$} \\
\hline $\begin{array}{l}\text { preceding the interviews } \\
\text {-Missing }\end{array}$ & $\begin{aligned} 62.3(\underline{n}=81) \\
.8(\underline{n}=1)\end{aligned}$ & $\begin{array}{c}73.3(\underline{n}=55) \\
1.3(\underline{n}=1)\end{array}$ & $\begin{array}{l}48.1(\underline{n}=26) \\
0\end{array}$ & $8.52^{* *}$ \\
\hline${ }^{*} p \leq .05 \quad{ }^{* *} p \leq .01$ & & & & \\
\hline
\end{tabular}


Appendix Table 5

Frequency Dlstribution of Self-Perceived Health Status

\begin{tabular}{|c|c|c|c|}
\hline Self-Perceived Health & Sample & Social Assistance & Working Poor \\
\hline Poor & $21.5 \%(\underline{n}=28)$ & $30.3 \%(\underline{n}=23)$ & $9.3 \%(\underline{n}=5)$ \\
\hline Fair & $28.5 \%(\underline{n}=37)$ & $31.6 \%(\underline{n}=24)$ & $24.1 \%(\underline{n}=13)$ \\
\hline Good & $35.4 \%(\underline{n}=46)$ & $28.9 \%(\underline{n}=22)$ & $44.4 \%(\underline{n}=24)$ \\
\hline Very Good & $10.8 \%(\underline{n}=14)$ & $7.9 \%(\underline{n}=6)$ & $14.8 \%(\underline{n}=8)$ \\
\hline Excellent & $3.8 \%(\underline{n}=5)$ & $1.3 \%(\underline{n}=1)$ & $7.4 \%(\underline{n}=4)$ \\
\hline
\end{tabular}

Chi-square $=13.68 ; p<.01$

ApPendix Table 6

Means (Standard Deviations) for Continuous Health Status Variables

\begin{tabular}{lcccc}
\hline & Sample & Social Assistance & Working Poor & T-Value \\
\hline Medical Conditions & 1.8 & 2.2 & 1.1 & $-3.63 \dagger$ \\
Symptoms of Illness and/or Disease & $(1.9)$ & $(2.0)$ & $(1.6)$ & \\
Mental Health Inventory (MHI) Score & 3.0 & 3.5 & 2.4 & $-3.30 \dagger$ \\
& $(2.1)$ & $(2.2)$ & $(1.8)$ & \\
& $(48.6$ & 47.5 & 50.2 & 1.09 \\
\hline
\end{tabular}

tp $\leq .001$ (2-tail)

\section{ApPendix Table 7}

Proportions and Chi-Square Values for Activity Limitation Variables

\begin{tabular}{|c|c|c|c|c|}
\hline & Sample & Social Assistance & Working Poor & Chi-Square \\
\hline Experienced activity limitations & $53.8(\underline{n}=70)$ & $64.5(\underline{n}=49)$ & $38.9(\underline{n}=21)$ & $8.32^{* *}$ \\
\hline $\begin{array}{l}\text { Severity of activity limitations } \\
\text { Activities not limited } \\
\text { Somewhat limited } \\
\text { Limited quite a bit } \\
\text { Limited a great deal/completely }\end{array}$ & $\begin{array}{l}46.2(\underline{n}=60) \\
23.1(\underline{n}=30) \\
15.4(\underline{n}=20) \\
15.4(\underline{n}=20)\end{array}$ & $\begin{array}{l}35.5(\underline{n}=27) \\
30.3(\underline{n}=23) \\
14.5(\underline{n}=11) \\
19.7(\underline{n}=15)\end{array}$ & $\begin{array}{c}61.1(\underline{n}=33) \\
13.0(\underline{n}=7) \\
16.7(\underline{n}=9) \\
9.3(\underline{n}=5)\end{array}$ & $10.92^{\star \star}$ \\
\hline $\begin{array}{l}\text { Frequency of activity limitations } \\
\text { Activities not limited } \\
\text { A few times/month } \\
1-6 \text { times/week } \\
\text { Every day }\end{array}$ & $\begin{array}{l}46.2(\underline{n}=60) \\
16.2(\underline{n}=21) \\
18.5(\underline{n}=24) \\
19.2(\underline{n}=25)\end{array}$ & $\begin{array}{l}35.5(\underline{n}=27) \\
17.1(\underline{n}=13) \\
21.1(\underline{n}=16) \\
26.3(\underline{n}=20)\end{array}$ & $\begin{array}{c}61.1(\underline{n}=33) \\
14.8(\underline{n}=8) \\
14.8(\underline{n}=8) \\
9.3(\underline{n}=5)\end{array}$ & $10.02^{*}$ \\
\hline${ }^{*} p \leq .05 \quad * * p \leq .01$ & & & & \\
\hline
\end{tabular}

